\title{
Mumbai Metro Line-3: Initial Drive of Tunneling Activities in Package 04
}

\author{
Ojas Vora ${ }^{1}$, Avinash More ${ }^{2}$ andE.Thinakaran ${ }^{3}$ \\ ${ }^{1}$ Student, ${ }^{2 \& 3}$ Assistant Professor, Rizvi College of Engineering, Mumbai University, Maharashtra, India \\ E-Mail: ojas.pankaj.vora@gmail.com,avinahmore46@gmail.com, thinak8@gmail.com
}

\begin{abstract}
Mumbai Metro Line -3, indicated as the ColabaBandra-Seepz line, is a part of the metro system of the city and is the first underground covering, $33.50 \mathrm{~km}$ metro line in Mumbai, India. The study area of the tunnel line is between Naya Nagar tunnellaunching shaft and Siddhivinayak Metro station, which is part of Package 04. The distance between these two locations is about $3.6 \mathrm{~km}$. The description about the initial drive of tunneling activities, which involves Installation of Piles, Anchoring, lowering of TBM(Tunnel Boring Machine), Mining, Shoving, Mucking, Ring Building and Grouting has been detailed in accordance with the site condition. From the environmental point of view, the problems such as deforestation and flooding have been discussed along with the remedial action.
\end{abstract}

Keywords: Mumbai Metro Line-3, Package 04, Tunneling Activities, Environmental Impacts

\section{INTRODUCTION}

Mumbai metro line-3 has been planned to connect Cuffe Parade to Santacruz Electronics Export Processing Zone (SEEPZ), a Special Economic Zone in Mumbai consisting of 26 underground stations and one at grade station. Metro Line 3 is planned to curtail the road congestion and load on the western line [6, p68]. Moreover, this Metro Line-3 (ColabaBandra-Seepz) is planned to connect the domestic and international terminals of Mumbai Airport, with Metro Line and terminals at SEEPZ. Special feature of this Metro Line-3 is the underwater metro rail tunnel which connects Kurla Complex and Dharavi stations with $1.2 \mathrm{~km}$ length. The construction is under progress and is expected to be completed by 2021 according to Mumbai Metro Rail Corporation (MMRC). In this paper, the details about the initial drive of tunneling activities involved along with the environmental impacts in Mumbai Metro Line -3, Package Underground Construction(UGC-04) have been reviewed.

\section{DETAILS AND DESCRIPTION ABOUT THE CHOSEN SITE}

Mumbai Metro Line -3, which is from Colaba to Seepz has been divided into seven packages out of which the details about package 4 (Naya Nagar - Dadar - Siddhivinayak, Fig 2.1)have been studied. Two tunnels with diameter of 5.8 meters have been excavated betweenNaya Nagar tunnel launching shaft and Siddhivinayak metro station. One of the tunnels is launched from Naya Nagar shaft towards Dadar station where the tunnel is received. The other tunnel is launched from Siddhivinayaktowards Dadar station where it is received. Dadar acts as the mid-point for the proposed stretch and falls in between Naya Nagar launching shaft and Siddhivinayak station. The tunnels excavated between Naya Nagar shaft and Siddhivinayak station are 24metres below the ground level and the shaft is 48metres in width. The up line distance from Naya Nagar to Siddhivinayak is $3.6 \mathrm{~km}$ whereas the downline distance is $3.602 \mathrm{~km}$ and hence the total mining length of the tunnel is $7.202 \mathrm{~km}$. The tunnel will have rings, which comprises tunnel segments which are proposed to be 2572 in number on the upline and 2574 on the downline, which sums to be 5146 for these two points.

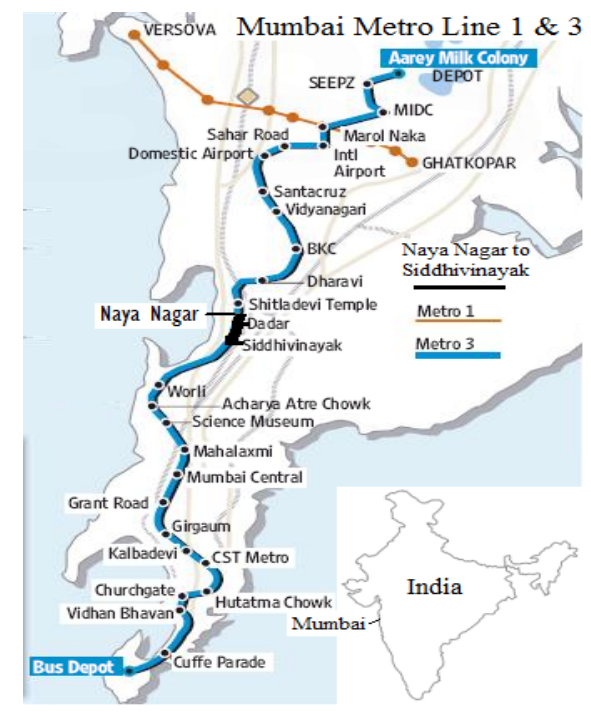

Fig. 1 Package UGC 04: Mumbai Metro Line-3

\section{A. Tunnel Boring Machines (TBM)}

Tunnel Boring Machines (TBMs) are being used in order to excavate the tunnels proposed in the project. The type of TBMs that are being used are Earth Pressure Balance Machines (EPBMs). These EPBMs work with the help of hydraulic jacks and these jacks are used to push these machines ahead [9, pp. 598-599]. Earth Pressure Balance Machine exerts earth pressure in the soil strata, below the pile foundation. So, the soil becomes tight and absorbs the vibration caused due to the machines and also prevents the above structure from collapse. These TBMs have been lowered at the launching shaft by a 150 tonne gantry craneand have the cutterhead diameter of 6.620 meters. The 
bore diameter of the tunnel is 5.8 metres with the thickness at the top and bottom being 0.275 metres. The consideration of thickness is helpful to know the amount of voids which need to be filled at the time of grouting.

\section{B. Tunnel Boring Machine (TBM) working principle in Initial Drive}

1. After the TBM has been lowered by the gantry crane, the first temporary segment ring is unloaded into the shaft. This first temporary ring is installed behind the TBM and bolted with the shoving frame with the help of straight bolts.

2. The TBM is pushed forward with the help of thrust jack for a distance of $1400 \mathrm{~mm}$.

3. Then the second temporary segment ring is similarly installed as the earlier one [8, pp. 1135-1136].

4. Similarly, the TBM is again pushed forward by the help of thrust jacks.

5. After the installation of third ring, the TBM begins to excavate the mixed-face ground using the cutterhead of the TBM.

6. Then after the desired length is reached, then the TBM is stopped and the segment rings are installed.This cycle keeps rotating for all the segment rings which are to be installed.

\section{TUNNEL ACTIVITIES PERFORMED IN PACKAGE UGC-04}

Flow Chart shows the order of the activities that have been carried out in package UGC-04 for the initial drive of 110metres.

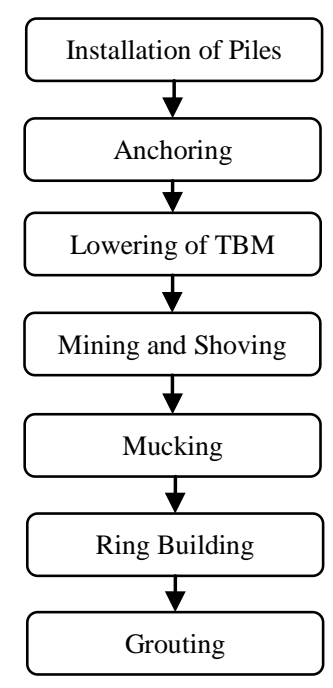

Fig. 2 Flow Chart

\section{A. Installation of Piles}

Secant piles are being installed at the metro station in order to stabilize the structure by bearing the load and to ensure that the structure does not collapse in future. Soft piles (without steel reinforcement and M20 grade concrete used) and hard piles (with steel reinforcement and M40 grade concrete used) have been placed alternately. The pile has a diameter of $800 \mathrm{~mm}$ with $40 \mathrm{~mm}$ casing on both the sides, which makes it $880 \mathrm{~mm}$. The equipment used for the piling is the rig machines (70 to 80 tonne rig machine, 55 to 60 tonne rig machine and 60 to 70 tonne rig machines). Installation of piles begins by marking the survey point using the total stations. Secondly, augers of $600 \mathrm{~mm}$ diameter are used for hard pile in order to cut the ground till the desired length. Next, the casing is fixed in order to avoid the interruption of mud. After that, the boring operation commences and simultaneously the auger keeps cutting the ground up to the desired length.

Once the desired length is reached, then the sounding chain is used to check the length of the pile, which is known as terminating length. Then the steel reinforcement cage is inserted into the pile. After that tremie pipes are inserted into the pile along with the hopper at top, which helps in allowing the concrete to pass through it and pipes help in the compaction of concrete. At the end the concrete is added to the pile and once it reaches at the top, the tremies are slowly removed out, compaction is done and after that the casing is removed [5, pp. 8-9]. A sample hard pile reading is given below:

1. Pile -689-Hard (Pile ID)

2. Diameter of pile $=800 \mathrm{~mm}$

3. G.W.T. (Guide Wall Table) $=(+) 4.50 \mathrm{~m}$

4. Formation Level (F.L) $=(-) 16.30 \mathrm{~m}$

5. Total Depth $=16.30+4.50=20.80 \mathrm{~m}$

Tremie Pipes - 20.5 m length (may vary as per design) are used for concrete boring (concrete is passed through them) and they are also used for tamping the concrete after it is passed through it.

Lengths of tremie pipes used:

1. Length of $1^{\text {st }}$ tremie pipe $=4.50 \mathrm{~m}$

2. Length of $2^{\text {nd }}$ tremie pipe $=4.30 \mathrm{~m}$

3. Length of $3^{\text {rd }}$ tremie pipe $=4.60 \mathrm{~m}$

4. Length of $4^{\text {th }}$ tremie pipe $=7.10 \mathrm{~m}$

Total length $=4.50+4.30+4.60+7.10 \mathrm{~m}=20.50+$ Hopper

Length of the Sounding Chain (Used for measuring the length of the bore) $=10.8 \mathrm{~m} \mathrm{x} 2=21.6 \mathrm{~m}$

Casing diameter $=700 \mathrm{~mm}=0.7 \mathrm{~m}$

Therefore, Boring length $=21.6-0.7=20.9 \mathrm{~m}$

This is the length at which the pile is terminated.

\section{B. Anchoring}

Anchoring is done to prevent the collapse of pile which occurs due to the lateral earth pressure [4, pp6]. At the beginning, a protection cover known as the whaler beam is constructed. Next, the drilling of the hole for the anchor is done by the head cutter. The anchor consists of simple wire, 
3 PVC pipes (for protection from corrosion) and the grout pipe. Anchor with diameter of $150 \mathrm{~mm}$ is placed at an inclination of $38^{0}$ using the angle definer at depth of 20-25 metres. This anchor contains a slotter at the mouth which is the first component to go into the hole drilled and starts cutting the inside portion whenever the simple wire gets stuck inside. Anchoring is done manually and takes around 50 minutes to get over. Once the entire anchor is inserted into the hole and reaches the desired depth, then the grouting takesplace. Here, two types of grouting are done which are primary and post grouting. Primary grouting is done at first and every void is tried to fill.Post grouting is done by allowing the grout to overflow a bit to ensure that all the voids are completely filled.

\section{Mining and Shoving}

After the TBMs were lowered using 150 tonne Gantry crane, the process of mining and shoving is commenced. The TBM had been pushed forward with the help of hydraulic jacks. There are a total 16 pairs of hydraulic jacks numbered as 2,4,6,8,10,12,14 and 16 [8, pp.1135-1136].The cutter head of TBM has a speed of 2.8 R.P.M (rotations per minute) with a face pressure of $1.8 \mathrm{~atm}$. The mining activity is carried out by the excavator along with the continuous cutting of the ground by the TBM. As the amount of mining is completed, chainages and the shoving length are all monitored continuously using a German Software known as VMT. If the TBM has some technicality issues and the cutterhead stops to rotate, then immediately VMT software detects it and sends a signal to the person monitoring the process. These processes are carried out under the initial drive which is up to a length of $110 \mathrm{~m}$.

\section{Mucking}

Once the mining commenced, and the cutter head of TBM started excavating the tunnel, there was lots of loose soil and mud which is generally termed as "Muck", which starts getting collected [9, p599]. Since, the activity is still in initial drive, the bucket used for mucking is smaller: $4 \mathrm{~m}^{3}$ capacity. Also, a small muck pit is constructed to store the muck. Mucking requires much better transportation facilities in order to increase the speed of the activity. Locomotive which has been checked and declared fit to use by the third party, is being used in order to move the bucket containing muck from the inside portion of tunnel to the outside part. The average estimated time for one cycle of mucking is approximately $18-20$ minutes.

\section{E. Ring Building}

Ring Building is dependent on Mining and Shoving length (Length when the hydraulic jack is extended outward). A ring consists of 6 components, which are called as Tunnel Segments. These segments are named as, Ordinary 1, Ordinary 2, Ordinary 3 (O1, O2, and O3), Tapered 1, Tapered 2 (T1 and T2) and Key (K). These segments are erected by the erector of the TBM. The key is the smallest component which locks or unlocks the entire ring. Moreover, the key position is the one which decides the direction of erection of segments. The basic rule of ring building is to place the key between two tapered segments (T1 and T2). The required shoving length for ring building is $1850 \mathrm{~mm}$. Depending on the strata, it normally takes 7 to 8 hours in achieving the mining length mentioned in the design. After fulfilling both these conditions, the next ring can be built[7, p.315]. It takes one hour and thirty minutes to build a ring, with the "Key" erection consuming more time. Butdepending on the strata, it takes an ample amount of time to achieve the mining length required for the ring to be built. A sample ring building reading is given below:

Name of the Ring Built- P-31 in TBM 1 (1073)

1. Segment ID:

Ordinary-1-M-8-0482-21-08-17

Ordinary-2-M-1-0483-21-08-17

Tapered-2-M-7-0481-21-08-17

Ordinary-3-M-7-0481-21-08-17

Tapered-1-M-7-0489-23-08-17

Key-M-4-0398-24-07-17

2. Time for mining $=7$ hours.

3. Tail shield to top segment (Terrestrial Clearance) for 16 pairs of Jacks numbered as 2,4,6,8...16.

For $2^{\text {nd }}$ Jack $=362 \mathrm{~mm}$

For $4^{\text {th }}$ Jack $=358 \mathrm{~mm}$

For $6^{\text {th }}$ Jack $=365 \mathrm{~mm}$

For $8^{\text {th }} \mathrm{Jack}=370 \mathrm{~mm}$

For $10^{\text {th }} \mathrm{Jack}=364 \mathrm{~mm}$

For $12^{\text {th }}$ Jack $=355 \mathrm{~mm}$

For $14^{\text {th }}$ Jack $=342 \mathrm{~mm}$

For $16^{\text {th }}$ Jack $=362 \mathrm{~mm}$

4. Plum: Look up and Overhang

Left Lid $=10 / 4740 \mathrm{c} / \mathrm{c}$

Right Lid $=10 / 4800 \mathrm{c} / \mathrm{c}$

5. Chainage Mark $=18631.00 \mathrm{~mm}$

Deflection from Left Lid $=1.999 \mathrm{~mm}$

Deflection from Right Lid $=2.010 \mathrm{~mm}$

\section{F. Grouting}

Pressure grouting is done to fill the voids left after the completion of ring building. If the ring building is done for positon P33 then the grouting has to be started for ring P31, which is the alternate position. Cement, sand and bentonite are mixed and are transferred through grout pipes into the voids. Sodium Silicate is also added to that grout $(12 \%$ of the total grout in quantity) for rapid hardening which increases the initial setting time [1, Clause 10.2, p2]. The bore diameter of tunnel is 5.8 metres whereas the pre grout tests are performed before the grout is decided safe to use.

Some of the readings observed are mentioned in Table I and II.

TABLE I PRE GROUT TEST 


\begin{tabular}{|c|c|c|c|c|c|}
\hline Date & 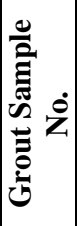 & 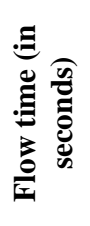 & 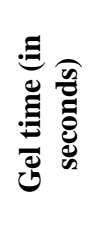 & 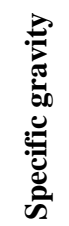 & 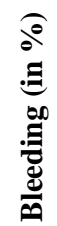 \\
\hline $21 / 12 / 2017$ & 1. & 16.38 & 11.33 & 1.33 & \\
\hline Day Shift & 2. & 16.97 & 11.96 & 1.33 & $1 \%$ \\
\hline 9:50 am & 3. & 16.50 & 11.43 & 1.33 & \\
\hline $21 / 12 / 2017$ & 1. & 16.48 & 10.92 & 1.31 & \\
\hline Night Shift & 2. & 16.09 & 11.24 & 1.31 & $2 \%$ \\
\hline 9:30 pm & 3. & 16.32 & 11.08 & 1.31 & \\
\hline
\end{tabular}

The TableI shows the result of the various tests which are being carried out before grout is declared fit to use. Flow test is done in order to check the flow time of the grout. The average flow time of the samples must be in the range of 8 seconds to 20 seconds, only then it is declared fit to use[2, Clause 9, p2]. Gel time is to check the time taken by the grout to gel (set), the average gel time of the samples should be within permissible limit which is in the range of 7 to 15 seconds (as per design). The specific gravity test is done using a hydrometer and as per design, the average specific gravity should be less than 1.6. For bleeding test, the allowable limitis less than $5 \%$ [3, Clause 11, p2]. Only if the grout satisfies all these conditions, it is declared fit to use.

TABLE II STRENGTH TEST FOR GROUT (PRE GROUT-TEST)

\begin{tabular}{|c|c|c|c|c|}
\hline $\begin{array}{c}\text { S. } \\
\text { No. }\end{array}$ & $\begin{array}{c}\text { Weight } \\
\text { of Cube } \\
\text { (in Kg) }\end{array}$ & $\begin{array}{c}\text { Compressive } \\
\text { Strength } \\
\text { (in N) }\end{array}$ & $\begin{array}{c}\text { Area of } \\
\text { Cube (in } \\
\mathbf{m m} \text { } \mathbf{~ m m} \text { ) }\end{array}$ & $\begin{array}{c}\text { Stress } \\
\text { (in } \\
\mathbf{N} / \mathbf{m m}^{2} \text { ) }\end{array}$ \\
\hline 1. & 0.16 & 1000 & $40 \times 40$ & 0.625 \\
\hline 2. & 0.1624 & 963 & $40 \times 40$ & 0.602 \\
\hline 3 & 0.1624 & 966 & $40 \times 40$ & 0.604 \\
\hline
\end{tabular}

The Table II shows the test results for 1hour strength test of the grout. This is done before the grout is allowed to pass intothe segments. The experiment is performed using the Compressive Testing Machine, and if the reading shows the strength to be above $700 \mathrm{~N}$ (as per design), then the grout is allowed to use. So in the above cases all the 3 results are satisfying the given condition so they can be used. In order to calculate the compressive stress, we use the formula,

\section{Compressive stress $=\underline{\text { Load }(\text { Compressive strength in } \mathrm{N})}$ Area of the Cube (in $\mathrm{mm}^{2}$ )}

The resulting compressive stress should be greater than $0.2 \mathrm{~N} / \mathrm{mm}^{2}$ (as per design) since all the conditions are satisfied, the grout is declared fit to use.After these tests, batching of the grout is done and the grout is sent in batches to the voids that need to be filled in the ring. The results of total volume and pressure during grouting are shown in Table III.
TABLE III PRESSURE AND VOLUME DURING GROUTING

\begin{tabular}{|c|c|c|c|c|c|c|}
\hline 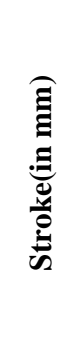 & 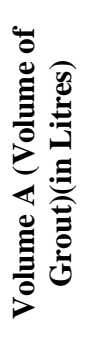 & 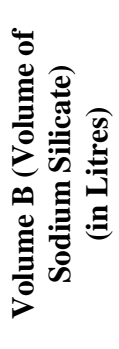 & 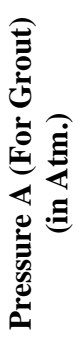 & 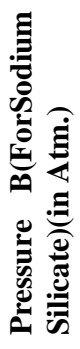 & 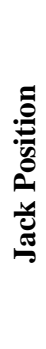 & 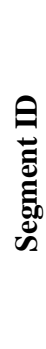 \\
\hline 459 & 3440 & 390 & 3.1 & 5.6 & 15 & $\mathrm{~T}_{1}$ \\
\hline 1825 & 1000 & 120 & 3.2 & 5.9 & 2 & $\mathrm{O}_{3}$ \\
\hline Total & 4440 & 510 & & & & \\
\hline
\end{tabular}

The Table III shows the pressure and volume results during grouting. The total volume has been calculated by adding volume of grout and volume of sodium silicate and the answer: $(4440+510=4950)$ liters.

Sodium silicate added is within permissible limit which is in the range of 10 to12\% of grout. (as per design).

Hence,

$$
\text { Percentage of sodium }=\frac{\text { Volume of sodium } \mathrm{x} 100}{\text { Volume of grout }}
$$

This is found to be $11.49 \%$ which is O.K.

Then the total shoving length = difference in the stokes readingwhich is calculated as,(1825 - 459=1366) mm. Tail void ratio is 3.27 and hence the volume of tail void is calculated as, Volume of tail void $=$ Tail void ratio $\mathrm{x}$ difference in stokes which is $(3.27 \times 1366=4467)$ liters approximately.

Finally, the total percentage is calculated as,

Total percentage $=\underline{\text { Total Volume } \times 100}$

Volume of tail void

Total Percentage is found to be $110.81 \%$

Approximately111 \%

\section{IMPACTS ON THE ENVIRONMENT}

Whenever a big project is under construction in a metropolitancity, there are several environment related issues to be expected. Likewise, some of the drawbacks found during Metro Line Project, which are cutting of trees and risks of flooding $[7,314]$.

\section{A. Cutting of trees}

Cutting of around 5000 trees across the city, will lead to various ill effects. The environmental impacts are not only to the environment but also to the health of its citizens. The project requires the cutting of approximate 1300 trees and rest of the 3700 trees has been proposed to be replanted by the MMRC. In the package UGC-04, there was an estimate 
150 trees which were cut down for construction purpose. The contractors are supposed to plant around2000 trees, after the completion of project. Meanwhile, the MMRC has planned to donate 25,000 saplings as a compensation for the losses.

\section{B. Risk of Flooding}

The underground metro construction is proposed to be constructed at least $15-30 \mathrm{~m}$ below the Mean Sea Level (M.S.L). Mumbai City being located 3-5 meters above M.S.L. and along the coast line will be affected to a huge extent which would result in flooding of metro subways. To control the flooding, storm water drain and pumping system should be planned properly.

\section{RESULTS AND DISCUSSION}

The geology observed at the site was mixed type and hence hard piles were inserted between two soft piles. The depth of the pile was in the range of 20-23 metres. Pre Grout Tests which include flow test, gel test, bleeding test, specific gravity and strength test were carried out in order to check whether the material used for grouting is fit for use. Table 3.2 shows the test results obtained. The average flow time was approximately 16 seconds which was in the range of 8 seconds to 20 seconds. The average gel time was 11 seconds which is within permissible limit of 7 to 15 seconds. Table 3.3 shows the test results of compressive strength. As per the design specifications, the compressive strength was found to be above $700 \mathrm{~N}$. The compressive stress was found to be approximately $0.6 \mathrm{~N} / \mathrm{mm}^{2}$ which was above 0.2 $\mathrm{N} / \mathrm{mm}^{2}$.

\section{CONCLUSION}

The Mumbai Metro Line 3 promises to solve almost $15 \%$ of the traffic congestion problems faced by Mumbai City. It also aims to lessen the load of 7 million commuters on the local trains of Mumbai in which more than 9 people lose their lives every day due to overcrowding. The metro aims at carrying 1.7 million passengers on daily basis and it also ensures to keep the city moving which comes to a halt when trains are not running due to technical reasons. It also links the main stations of the cities to the airport which was the major concern with the local Mumbai trains. But along with the positives, the officials need to look at the problems such as flooding and constant cutting of trees. The flooding issue can be solved to an extent by installation of water evacuation pumps along with their own drainage systems in case of rains. Moreover, they need other drainages which will not only drain the water, but also hold the excess water which can further be utilised. In case of trees, there is a requirement of planting at least 4 times the number of trees which have been cut down.

\section{REFERENCES}

[1] ASTM C938-10, "Standard Practice for Proportioning Grout Mixtures for Preplaced-Aggregate Concrete”, ASTM Standards International,United States of America, pp. 1- 4, 2010.

[2] ASTM C939-02, "Standard Test Method for Flow of Grout for Preplaced-Aggregate Concrete (Flow Cone Method)", ASTM Standards International, United States of America, pp. 1- 3, 2002.

[3] ASTM C940-98a, "Standard Test Method for Expansion and Bleeding of Freshly Mixed Grouts for Preplaced-Aggregate Concrete in Laboratory", ASTM Standards International, United States of America, pp. 1- 2, 1998.

[4] A.D. Barley, D.A. Bruce, M.E.C. Bruce and J.C. Lang, "High Capacity and Fully Removable Soil Anchors", 27 ${ }^{\text {th }}$ Annual Conference on Deep Foundations, San Diego, CA, pp. 1-9, 2002.

[5] H. Suroor, M. Galagoda and C. McGheee, "Design and Construction of Circular Secant Pile Walls in Soft Clays", 6th International Conference on Case Histories in Geotechnical Engineering, Arlington, VA, pp. 1-11, 2008.

[6] N. Sharma, R.Dhyani and S. Gangopadhaya, "Critical Issues Related to Metro Rail Projects in India”,Journal of Infrastructure Development, Vol.5, No.1, pp. 67-86, 2013.

[7] V. R. Pol and M. S. Ranadive, "Metro Tunneling- A Challenge", International Journal of Earth Sciences and Engineering, Vol.8, No.2, pp. 313-319, 2015.

[8] S. Ho Cho, J. Kim, J. Won and M. Kim, "Effects of Jack Force and Construction Steps on the Change of Lining Stress in a TBM Tunnel”, KSCE Journal of Civil Engineering, Vol.21, No.4, pp. 11351146, 2017.

[9] X. Haibo, L. Zhibin, and Y.Huayong, "Pressure Regulation for EarthPressure Balance Control on Shield Tunneling Machine by using Adaptive Robust Control”, Chinese Journal of Mechanical Engineering, Vol. 29, No.3, pp. 598-606, 2016. 